
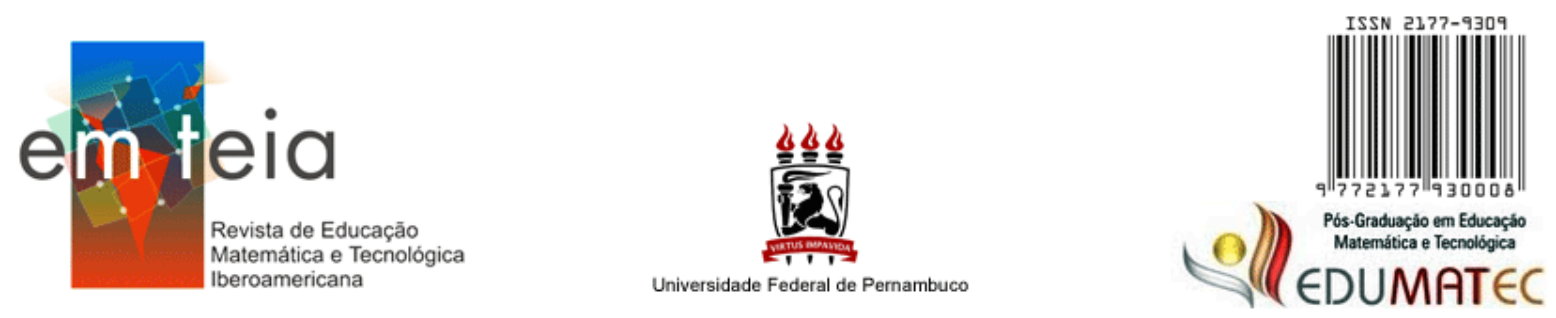

\title{
A PRESENÇA DE IDEIAS DE ROUSSEAU, PESTALOZZI E PIAGET NAS PESQUISAS BRASILEIRAS SOBRE O LABORATÓRIO DE ENSINO DE MATEMÁTICA
}

\author{
Fernando Guedes Cury \\ matfernando@yahoo.com.br
}

\begin{abstract}
Resumo
O texto traz os resultados de uma pesquisa bibliográfica que buscou verificar se trabalhos de mestrado e doutorado brasileiros ligados a laboratórios de ensino de matemática (LEM) fazem referência a Rousseau, Pestalozzi e Piaget, pensadores suíços que enfatizavam a ação do indivíduo sobre os objetos como importante para a aprendizagem. Apresentamos, para isso, algumas ideias que sustentam os argumentos favoráveis ao ensino de matemática a partir dos LEM, do uso de materiais manipulativos e de atividades lúdicas e experimentais. Constatamos que a maioria das pesquisas observadas, mesmo que não discuta diretamente obras daqueles três nomes da educação, aponta argumentos que se relacionam às suas propostas de ensino pautadas na observação, experimentação e manipulação de materiais concretos precedendo atividades com entes abstratos.
\end{abstract}

Palavras-chave: Rousseau. Pestalozzi. Piaget. Laboratório de Ensino de Matemática.

\section{The Presence of Rousseau, Pestalozzi and Piaget's Ideas in the Brazilian Researches on the Laboratory of Mathematics Teaching}

\begin{abstract}
This text presents the results of a bibliographical research that aims to verify if Brazilian masters and doctoral studies about laboratory for teaching Mathematics (LTM) have made reference to Rousseau, Pestalozzi and Piaget, Swiss thinkers who emphasized individuals actions on objects as important for learning. For this, we present some ideas that support the arguments favorable to the teaching of mathematics from the LTM, the use of manipulative materials and experimental activities. We find that even if most of the observed researches do not use directly the discusses of those three names of education, they point out arguments that are related to their teaching proposals based on observation, experimentation and manipulation of concrete materials preceding activities with abstract entities.
\end{abstract}

Keywords: Rousseau. Pestalozzi. Piaget. Laboratory for Teaching Mathematics. 


\section{Introdução}

Há alguns anos nosso trabalho na formação de professores de matemática nos levou à coordenação de um Laboratório de Ensino de Matemática (LEM) e, por causa dele, nos envolvemos em leituras sobre o tema. Numa delas, a do livro O Laboratório de Ensino de Matemática na Formação de Professores, organizado por Sérgio Lorenzato (2006), vários autores apresentam suas concepções e propostas sobre o LEM, as justificativas para sua implantação e para o uso de materiais didáticos manipuláveis ou manipulativos (MD), considerados ferramentas ricas ao ensino e aprendizagem desta disciplina e importantíssimos à formação docente. Já nas primeiras páginas desse livro o valor dado ao apoio visual-tátil para facilitar a aprendizagem é destacado como algo já defendido há muito tempo:

Comenius escreveu que o ensino deveria dar-se do concreto ao abstrato, justificando que o conhecimento começa pelos sentidos e que só se aprende fazendo. Locke, em 1680, dizia da necessidade da experiência sensível para alcançar o conhecimento. Cerca de cem anos depois, Rousseau recomendou a experiência direta sobre os objetos, visando à aprendizagem. Pestalozzi e Froebel, por volta de 1800, também reconheceram que o ensino deveria começar pelo concreto. /../ Mais recentemente, Montessori legou-nos inúmeros exemplos de materiais didáticos e atividades de ensino que valorizam a aprendizagem através dos sentidos, especialmente do tátil, enquanto Piaget deixou claro que o conhecimento se dá pela ação refletida sobre o objeto; Vygotsky, na Rússia, e Bruner, nos Estados Unidos, concordaram que as experiências no mundo real constituem o caminho para a criança construir seu raciocínio (LORENZATO, 2006, pp. 3-4, itálicos nossos).

Para além de uma referência quase obrigatória a pesquisas, planos de ensino, trabalhos e projetos que tratam de abordagens didático-pedagógicas da educação matemática ligadas ao uso de material concreto, jogos e ludicidade, a obra de onde extraímos a citação acima pode ser considerada um "clássico" dos cursos de licenciatura em matemática no Brasil e também da Educação Matemática brasileira, tal como indicam Rodrigues, Silva e Ferreira (2016). O livro de Lorenzato traz, em oito capítulos assinados por 11 pesquisadores da área, discussões envolvendo o trabalho nesse ambiente e seus fundamentos teórico-metodológicos.

A concepção de LEM que conduz este texto é baseada na coletânea de Lorenzato (2006), ou seja, ele pode ser espaço físico específico, mas, mais que isso, é um ambiente que é usado para aulas e para os alunos eliminarem suas dúvidas; para os professores planejarem suas atividades (aulas, exposições, olimpíadas, avaliações...) e discutirem seus projetos, tendências e inovações; para a criação e o desenvolvimento de atividades experimentais, 
inclusive para a produção de materiais instrucionais que possam facilitar o aprimoramento da prática pedagógica, como jogos e vídeos.

A partir daí e da motivação dada pelas discussões e conferências ocorridas no VII Conversaciones Pedagógicas: influencias suizas en la educación española e iberoamericana $^{1}$, procuramos verificar como apareciam em pesquisas brasileiras envolvendo o Laboratório de Ensino de Matemática algumas das orientações de Rousseau, Pestalozzi e Piaget que (além de suíços) tinham em comum discursos sobre ensino e de formação que valorizavam a ação direta do indivíduo sobre objetos e a observação de fenômenos naturais e físicos - compatíveis com o trabalho no LEM. O presente texto dedica-se aos primeiros resultados desse estudo.

Dessa forma, a seção seguinte tem o objetivo de situar o leitor em tais discursos; delinearemos resumidamente ideias dos três nomes suíços que, segundo já apontado pela citação do início deste texto, postularam há séculos justificativas que, segundo entendemos, embasam o trabalho com o LEM. Posteriormente, avaliamos como, em trabalhos de mestrado e doutorado brasileiros, essas referências têm aparecido.

Essa avaliação deu-se por uma pesquisa bibliográfica seguida de uma análise quantiqualitativa, conforme Goldenberg (2003). Num momento inicial, foi feito um levantamento no Banco de Teses e Dissertações do Portal da Coordenação de Aperfeiçoamento do Pessoal do Ensino Superior (CAPES) ${ }^{2}$. A busca no Portal foi feita usando os seguintes conjuntos de palavras-chave: "laboratório de ensino de matemática", "laboratório de educação matemática", "laboratório de ensino e aprendizagem da matemática" e "laboratório de matemática". Encontramos, então, 57 teses e dissertações. Acrescentamos a estas a pesquisa de mestrado de Ana Maria Mauiack de Oliveira (1983), pois tínhamos conhecimento de sua existência, mas ela não aparecia naquele banco de dados. Excluímos de nossa amostra os trabalhos que, mesmo que falassem do LEM, faziam abordagens que não tratavam de propostas para seu uso e o de jogos educativos ou MD nas aulas de matemática como, por exemplo, os que tratavam de laboratórios computacionais e uso de softwares, ou do LEM apenas usado como espaço para a coleta de dados para determinada pesquisa, ou ainda que nada tivesse a ver com o tema de nosso estudo, mas foram dados como resultado do buscador do Portal (16 trabalhos foram excluídos por esses motivos). Outros onze trabalhos não estavam disponíveis para download nesse Portal da CAPES nem foram encontrados em

\footnotetext{
${ }^{1}$ Ocorrido em novembro de 2016 na Universidade de Salamanca (Espanha).

${ }^{2}$ http://bancodeteses.capes.gov.br/banco-teses/\#/
} 
buscas paralelas na internet e nos sites dos Programas onde os mesmos foram desenvolvidos. Ficamos, então, com um total de 31 monografias, das quais tínhamos uma tese de doutorado, 11 dissertações de mestrado profissionalizante e 19 de mestrado acadêmico. Ainda nesse primeiro momento da investigação já buscamos aqueles trabalhos que apresentavam ou não trabalhos dos educadores suíços em suas referências.

Passamos, numa segunda etapa, a uma leitura mais atenciosa dos trabalhos selecionados procurando identificar como eles faziam referências às ideias que entendemos serem correlatas com as de Rousseau, Pestalozzi e Piaget - especialmente aqueles trabalhos que não faziam citações a trabalhos dos três suíços. Para esse tipo de leitura, pensamos ser fundamental que os assuntos a serem identificados estejam bem claros na mente do investigador já que o importante não é exatamente a identificação de palavras-chave para confirmar se um texto está falando de algo, mas deve-se tentar captar o que está "abaixo da superfície textual". Isto significou, em nosso caso, procurar quando os autores, ao apresentarem suas concepções educacionais, faziam menção a modelos de ensino que valorizassem o interesse e a inventividade dos estudantes, a aprendizagem por meio de (re)descoberta, destacassem a importância da observação de fenômenos ou experimentos, da ludicidade, da interação entre os alunos e a natureza. Além disso, procuramos por justificativas para o trabalho no LEM pautadas na importância que a interação com os materiais concretos tinham precedendo a passagem a tópicos abstratos, ou seja, a indicação de que o ensino deveria sempre partir da experimentação prática e sensorial para a teoria, do que já é conhecido para o novo. Se os textos trazem essas coisas, isto indica para nós que suas ideias se aproximam ou são compatíveis com a dos três autores que usamos como referências principais. Finalmente, concluímos o texto com considerações finais sobre todo esse o processo.

\section{Três Discursos Afinados: Rousseau, Pestalozzi e Piaget}

Jean Jacques Rousseau (1712-1778) nasceu em Genebra, mas seu nome está fortemente ligado à Revolução Francesa já que suas obras inspiraram os envolvidos naquele momento histórico. Pode-se dizer que no centro da sua obra há o destaque ao fato de "o homem ser bom por natureza", mas ele está submetido a uma constante influência corruptora da sociedade, entendida como falhas da civilização para atingir o bem comum. No campo pedagógico, destaca-se a obra Emílio ou da Educação (1762), livro que inspirou diretamente 
Pestalozzi, entre outros, e, depois, os signatários da Escola Nova, e onde sintetiza suas ideias para um sistema educativo, político, ético e religioso (GROSS; GRAMINHO, 2007).

Em Emílio, apoiado tanto em ideias romancistas quanto no imaginário iluminista, Rousseau conta a história de um garoto educado por um preceptor de forma livre, natural, valorizando a invenção e a descoberta. Apesar de a obra defender distintas formas de se educar homens e mulheres - apontando que "a mulher é feita especialmente para agradar ao homem" (ROUSSEAU, 1992, p. 424), devendo, para isso, ser educada para tarefas domésticas e não para a "natureza e a razão" -, a educação é vista como direito, indicada como ponte para transformações sociais: era uma clara oposição à pedagogia jesuíta, rígida, punitiva e transmissora hierárquica de conhecimentos memorizados.

Rousseau diz que nascemos "fracos, estúpidos e sem juízo", mas que podemos conseguir tudo o que precisamos pela educação vinda da natureza, dos homens ou das coisas:

O desenvolvimento interno de nossas faculdades e de nossos órgãos é a educação da natureza; o uso que nos ensinam a fazer deste desenvolvimento é a educação dos homens; e a aquisição de nossa própria experiência sobre os objetos que nos afetam é a educação das coisas.

Assim, cada um de nós é formado por três tipos de mestres. O discípulo em quem suas diversas lições se opõem é mal educado e jamais estará de acordo consigo mesmo; aquele em que todas elas recaem sobre os mesmos pontos e tendem aos mesmos fins vai sozinho para seu objetivo e vive consequentemente. Só esse é bem educado (ROUSSEAU, 1992, p. 11).

Em Emílio, Rousseau coloca-se a criticar os pais que tudo oferecem aos filhos dizendo que à criança que tudo o que quer consegue, "se imaginará dona do universo; encarará todos os homens como escravos; e quando enfim, formos forçados a recusar-lhe alguma coisa, ela, acreditando tudo ser possível quando manda, tomará a recusa por um ato de rebelião" (ROUSSEAU, 1992, p. 71). Outras de suas críticas sobre os modelos de educação da época (século XVIII) foram também direcionadas a governantes e professores dizendo, por exemplo, a estes últimos: "Começai portanto estudando melhor vossos alunos pois muito certamente não os conheceis" (ROUSSEAU, 1992, p. 6). Ele sugere uma postura em que o professor deve ensinar o que estaria mais próximo à vocação do seu aluno (educação natural). Rousseau é considerado preceptor da noção de infância e de educação voltada às suas capacidades e especificidades - diferentes das dos adultos.

No princípio da vida, quando a memória e a imaginação são ainda inativas, a criança só presta atenção àquilo que afeta seus sentidos no momento; sendo suas sensações o primeiro material de seus conhecimentos, oferecer-lhas [sic.] numa ordem conveniente é preparar sua memória a 
fornecer-lhas [sic.] um dia na mesma ordem a seu entendimento; mas como ela só presta atenção a suas sensações, basta primeiramente mostrar-lhe bem distintamente a ligação dessas sensações com os objetos que as provocam (Idem, p. 44, itálicos nossos).

$$
\text { I.../ }
$$

Transformemos nossas sensações em ideias, mas não pulemos de repente dos objetos sensíveis aos objetos intelectuais. É pelos primeiros que devemos chegar aos outros. Que os sentidos sejam sempre os guias em nossas primeiras operações do espírito: nenhum outro livro senão o do mundo, nenhuma outra instrução senão os fatos. A criança que lê não pensa, só lê; não se instrui, aprende palavras.

Tornai vosso aluno atento aos fenômenos da natureza, muito breve o tornareis curioso. Mas, para alimentar sua curiosidade, não vos apresseis nunca em satisfazê-la. Ponde os problemas ao seu alcance e deixe-o que os resolva. Que nada saiba, porque vós lho dissestes, e sim porque compreendeu sozinho. Que ele não se avizinhe à ciência, que a invente. Se jamais substituirdes em seu espírito a autoridade à razão, ele não raciocinará mais, não será mais do que o joguete da opinião dos outros (ROUSSEAU, 1992, p. 176, itálicos nossos).

\section{I.../}

Mas considerai primeiramente que, querendo formar um homem da natureza, nem por isso se trata de fazer dele um selvagem, de jogá-lo no fundo da floresta; mas que, entregue ao turbilhão social, basta que não se deixe arrastar pelas paixões nem pelas opiniões dos homens; que veja com sues olhos, que sinta com seu coração; que nenhuma autoridade o governe, a não ser sua própria razão. Nesta posição, é claro que a multidão de objetos que o impressionam, os freqüentes sentimentos que o afetam, os diversos meios de prover as suas necessidades reais, devem dar-lhe muitas idéias que nunca teria tido, ou que houvera adquirido lentamente. O progresso natural do espírito é acelerado, nunca invertido. $O$ mesmo homem que deve permanecer estúpido nas florestas deve tornar-se racional nas cidades, ainda que nelas seja simples espectador. Nada próprio a tornar sábios do que as loucuras que vemos sem compartilharmos; e mesmo aquele que as compartilha se instrui ainda, desde que não se iluda e não carregue o erro dos que as fizeram (ROUSSEAU, 1992, p. 291, itálicos nossos).

Como exemplificam esses trechos de Emílio, Rousseau, ao relatar de forma romanceada a educação de um jovem acompanhado de um preceptor e afastado da sociedade corruptora, propõe uma "educação conforme a natureza". Mas esse projeto não significa um retorno à vida selvagem ou primitiva, mas, por outro lado, indica uma recusa ao intelectualismo, ao ensino formal e livresco. Ele aponta para uma educação que privilegia o contato com a natureza e a contemplação de seus fenômenos. Valorizando, assim, a experiência, o aluno é mais ativo nesse processo e a curiosidade é um criador de questões e suas soluções.

Desse modo, o contato do jovem aprendiz com o mestre deveria ser de proximidade e amizade apreciando o contato e a observação da natureza e seus fenômenos. No modelo de educação proposto por Rousseau, os avanços aos tópicos mais complexos eram 
progressivamente administrados e a interatividade, a ludicidade, os interesses dos estudantes eram também valorizados.

As ideias de Johann Heinrich Pestalozzi (1746-1827) inspiraram diretamente pensadores como Froebel e Herbart e o seu nome está ligado a todos os movimentos de reforma da educação do século XIX. Ele antecipou-se ao movimento da Escola Nova que só se consolidou no início dos novecentos afirmando que a função principal do ensino deveria ser levar as crianças a desenvolver suas habilidades naturais e inatas.

Ao contrário de muitos de seus contemporâneos, Pestalozzi não concordava totalmente com a superestimação da razão humana: para ele só o amor tinha força capaz de levar o homem à plena realização moral. A escola idealizada e experimentada por Pestalozzi deveria ser não só uma extensão do lar - e daí a relação entre educação e amor muito presente em sua obra - mas também inspirar-se no ambiente familiar para oferecer uma atmosfera de segurança e afeto ao educando. A criança, em sua visão, se desenvolveria de dentro para fora e, assim, um dos cuidados principais do professor deveria ser respeitar os seus estágios de desenvolvimento, ou seja, o educador deveria ter como missão dar atenção à evolução do educando, às suas aptidões e necessidades, de acordo com as diferentes idades (SOËTARD, 2010).

Tanto a defesa de um olhar voltado ao ambiente natural quanto a construção de novos conceitos de criança, família e instrução escolar a que Pestalozzi se dedicou devem-se muito à sua leitura de Rousseau, personagem central do Iluminismo. Esses dois suíços acreditavam que o ser humano de seu tempo, cerceado por convenções sociais e influências que o distanciam de sua índole original, era sempre "bom".

Algumas de suas obras foram escritas como coleção de cartas, como em Como Gertrudes Instruiu seus Filhos, onde contempla várias de suas doutrinas pedagógicas. Na quinta carta dessa coletânea aponta mais claramente como o processo didático, por envolver necessidades físicas e mecânicas para o desenvolvimento do intelecto, deve obedecer a uma sequência: partir de elementos simples, adequar-se à concretude sensível da experiência infantil, aderir à situação concreta de sua existência. Nas palavras de Pestalozzi:

1. Todas as coisas que afetam os meus sentidos são, para mim, meios para alcançar as ideias exatas, somente como as suas imagens apresentam aos meus sentidos a sua essência invariável e imutável, em vez de suas variações mutáveis ou os aspectos particulares. Estes são, ao contrário, fonte de erros e de enganos se as suas imagens apresentam aos meus sentidos as suas propriedades acidentais em vez da sua essência.

2. A cada intuição, profundamente impressa no espírito humano e fixada na memória, se liga com grande facilidade e quase involuntariamente 
uma série de conceitos colaterais que estão mais ou menos em relação com aquela intuição.

3. Quando a essência de um objeto é impressa no teu espírito mais fortemente do que nos seus aspectos particulares, o mecanismo da tua natureza espontaneamente te guia, nos aspectos particulares deste objeto, dia a dia, de verdade em verdade. Ao contrário quando os aspectos variáveis de um objeto são impressos no teu espírito mais fortemente do que na sua essência, esse organismo da tua natureza, dia a dia, nos aspectos particulares deste objeto, te guia de erro em erro.

4. Aproximando objetos da mesma natureza, o nosso juízo sobre a sua verdade interna adquire uma maior amplitude, essencialidade e universidade, se faz mais penetrante e mais seguro /.../.

5. Também a intuição mais complexa consta de elementos simples. Se tens este em teu poder, também aquilo que é complexo se tornará simples.

6. Quanto mais sentidos você emprega ao indagar a essência ou as qualidades fenomenais de um objeto, tanto mais exata se torna o seu conhecimento sobre este (PESTALOZZI citador por SOËTARD, 2010, p. 62-63, itálicos nossos).

E é seguindo essas diretivas que o autor chegou a comparar o trabalho docente ao do jardineiro que devia providenciar as melhores condições para que as plantas (os educandos) seguissem seu desenvolvimento natural. Em outras palavras, o aprendizado seria, em parte, conduzido pelo próprio aluno com base na experimentação prática e na vivência intelectual, sensorial e emocional do conhecimento. É a ideia do "aprender fazendo", amplamente incorporada pela maioria das escolas pedagógicas posteriores a Pestalozzi. O método deveria partir do conhecido para o novo e do concreto para o abstrato, do sensível ou da experiência, para a teoria, progressivamente - sempre com ênfase na ação e na percepção dos objetos, mais do que nas palavras. O que importava, segundo Mesquida (2016), não deveria ser tanto o conteúdo, mas o desenvolvimento de habilidades e valores.

Em outra de suas obras, Cartas sobre Educación Infantil, contendo textos redigidos entre 1818 e 1819, há um escrito dedicado ao ensino de número, formas (geométricas) e linguagem. Nele, Pestalozzi diz que no ensino de aritmética os exercícios preparatórios deveriam sempre realizar-se de forma que à vista do aluno estejam objetos determinados para que lhe sirvam de unidades, pois uma criança pode inicialmente captar bem a ideia de duas bolas, duas rosas ou dois livros, mas não o conceito de "dois" em sentido abstrato. E tão logo a criança conheça as palavras que usamos para distinguir os números, podemos propor questões com operações simples de somar, subtrair, multiplicar e dividir, ainda com a ajuda de objetos (bolas, por exemplo) como unidades (PESTALOZZI, 1988). Após experiências realizadas usando essas sugestões, o autor indica algumas vantagens em comparação com o ensino abstrato das operações: 
Em primeiro lugar os alunos eram perfeitamente conscientes não só do que faziam, mas também do motivo pelo qual o faziam. /.../ faziam mais que se servir mecanicamente de uma fórmula, de modo que quando se mudava a forma da questão não caíam na confusão própria daqueles que só podem alcançar, nada mais do que lhes permite sua regra mecânica. /.../

A segunda vantagem era a de que as crianças que estavam familiarizadas com esses exercícios intuitivos elementares mostravam logo uma notável habilidade em cálculo mental (PESTALOZZI, 1988, p. 127, tradução nossa, itálicos do autor).

Para o ensino de geometria, o método indicado por Pestalozzi como exitoso em seus experimentos foi o que os antigos já chamaram de método analítico, ou seja, a

solução de problemas, planejá-los com base em casos concretos em vez de considera-los abstratos, e explicar de onde provem, em lugar de nos limitar a constatar sua existência. Este procedimento transforma a aprendizagem em descobridora, não se contentando com as descobertas já feitas pelos demais (PESTALOZZI, 1988, p. 128, tradução nossa).

Pestalozzi ainda defendia que o estudo da geometria não deve ser dirigido para o simples conhecer de relações de formas e medidas - que poderia ter, eventualmente, seu uso prático, inclusive no avanço da ciência - mas, acima de tudo, para o desenvolvimento do raciocínio lógico e da capacidade inventiva proveniente desse estudo (PESTALOZZI, 1988).

Já no século XX, uma das teorias mais importantes para a educação, a Construtivista, surgiu principalmente a partir das experiências do biólogo, filósofo e epistemólogo suíço Jean Piaget (1896-1980). Em seus estudos, observando crianças desde o nascimento até a adolescência, percebeu que o conhecimento se construía na interação do sujeito com o meio em que ele vive. Para ele, o conhecimento

não pode ser concebido como se estivesse predeterminado, nem pelas estruturas internas do sujeito, já que são uma construção efetiva e contínua, nem nas características preexistentes do objeto, uma vez que elas só são conhecidas graças a mediação necessária dessas estruturas, e que essas, ao enquadrá-las, enriquecem-nas (PIAGET, 1970, p. 8).

I.../

[O conhecimento] não procede em suas origens nem de um sujeito consciente de si mesmo nem de objetos já constituídos (desde o ponto de vista do sujeito) que lhe são impostos; mas sim, resulta de interações que se produzem no meio do caminho entre ambos e por isso depende de ambos, mas com uma indiferenciação completa e não como intercâmbio entre formas distintas (PIAGET, 1970, p. 14).

Piaget propôs em uma teoria sobre como se dá o processo de construção e atualização do conhecimento explicações para o desenvolvimento cognitivo da criança com base na experimentação psicológica científica. Até aquele momento, primeira metade dos novecentos, 
os métodos psicológicos se baseavam em testes padronizados - como os de QI (quociente de inteligência) - para avaliar a aptidão intelectual da criança. O método experimental de Piaget consistia em entrevistas, partindo de problemas abertos, com solução não diretamente aparente, para investigar os fundamentos e os processos cognitivos das crianças analisadas. Como aponta Gomes (2016), essa abordagem clínica não pretendia medir a capacidade intelectual das crianças observadas, mas buscava entender como a criança resolvia determinados problemas e, a partir daí, formulava suas concepções sobre a realidade.

Piaget concebia o desenvolvimento do conhecimento como um método espontâneo, ligado ao processo global da "embriogênese", isto é, ao desenvolvimento do corpo, do sistema nervoso e das funções mentais. Assim, assinala Gomes (2016), em geral a aprendizagem seria efetivada por situações promovidas por um experimentador psicológico; ou por um professor, com referência a algum ponto didático; ou por uma situação externa. Além disso,

Enquanto o desenvolvimento humano é espontâneo, a aprendizagem é condicionada por fatores externos ao sujeito. Mesmo assim, apesar de não ser uma teoria pedagógica ou de aprendizagem, a epistemologia genética revolucionou o modo de conceber a construção e o desenvolvimento do conhecimento humano e contribuiu na construção de inovações pedagógicas na medida em que o sujeito passa a ser visto como um ser capaz de construir seu próprio conhecimento na interação com o meio (GOMES, 2016, p. 39, itálicos do autor).

E foi a partir da epistemologia genética piagetiana que o construtivismo emergiu enquanto tendência pedagógica, passando, então, a influenciar fortemente as inovações do ensino da matemática. Essa influência, já destacava Fiorentini (1995), pode ser considerada positiva, já que trouxe maior embasamento teórico para a substituição de uma prática pedagógica mecânica, mnemônica e associacionista em aritmética por que visava, com o auxílio de materiais concretos, a construção das estruturas do pensamento lógico-matemático e/ou à construção de conceitos chave na matemática, como o de número e os relativos às quatro operações elementares da aritmética.

Na obra La Epistemología Genética o autor assim resume as primeiras fases da formação dos conhecimentos nas crianças, a Psicogênese:

A primeira etapa era a da função semiótica (até $1 \frac{1 / 2}{2} 2$ anos) que, com a interiorização da imitação em imagens e a aquisição de linguagem, permite a condensação das ações sucessivas em representações simultâneas. A segunda grande etapa é a do início das operações concretas que, considerando as antecipações e as retroações, alcança uma reversibilidade suscetível de retomar o curso do tempo e garantir a conservação dos pontos de partida. Mas já se pode falar, a este respeito, de uma mobilidade conquistada sobre a duração, ela permanece ligada a ações e manipulações que são sucessivas, EM TEIA - Revista de Educação Matemática e Tecnológica Iberoamericana - vol. 8 - número 1 - 2017 
pois, de fato, trata-se de operações que continuam 'concretas', isto é, se referem a objetos e transformações reais. Em oposição, as operações 'formais' assinalam uma terceira etapa em que o conhecimento ultrapassa $o$ próprio real para inserir-se no possível e para relacionar diretamente o possível ao necessário sem a mediação indispensável do concreto; ora, o possível cognitivo, como por exemplo, a sequência infinita de números inteiros, a potência do contínuo ou simplesmente as dezesseis operações resultantes das combinações de duas proposições p e q e de suas negações, é essencialmente extemporâneo, em oposição ao virtual cujas realizações se deslocam no tempo (PIAGET, 1970, p. 57-58, tradução nossa).

A partir daí, em vários de seus escritos Piaget questionou o pouco avanço das posições da ciência da educação, em comparação com as renovações profundas ocorridas na psicologia infantil e na sociologia, especialmente pelos estudos que ele vinha desenvolvendo. Ele defendia que programas e métodos didáticos deveriam, antes de implementados, passar por estudos sistemáticos controlados por métodos estatísticos e analisados segundo as diversas pesquisas psicossociológicas (PIAGET, 1985).

Adepto de uma concepção logicista da Matemática, Piaget não concorda com a ideia de que há crianças com mais aptidão (ou mais inteligentes) para o estudo da matemática. Por outro lado, ele acredita que o problema está na forma como o seu ensino se dá. Como o ensino dessa disciplina exige uma reflexão sobre as estruturas, o uso de uma linguagem técnica que contém um simbolismo muito particular e exige um grau mais ou menos alto de abstração, pode, segundo ele, “incidir sobre a compreensão da própria linguagem, em oposição às estruturas por ela descritas, ou sobre a velocidade de abstração enquanto se acha vinculada a um tal simbolismo e não enquanto reflexão sobre as estruturas naturais" (1985, p. 51).

Além disso, como a Matemática seria uma disciplina inteiramente dedutiva, se um aluno não compreende bem um determinado assunto, achará muito mais complexos os assuntos subsequentes. E conclui:

Numa palavra: o problema central do ensino das matemáticas é o do ajustamento recíproco das estruturas operatórias espontâneas, próprias à inteligência, e do programa ou dos métodos relativos aos domínios matemáticos ensinados. No entanto, esse problema alterou-se profundamente nas últimas décadas, em virtude das transformações das próprias matemáticas.

I.../

O problema pedagógico continua a ser, em sua totalidade, apesar do progresso de princípio realizado em torno das raízes naturais das estruturas operatórias, o de encontrar os métodos mais adequados para passar destas estruturas naturais, mas não reflexivas, para a reflexão sobre tais estruturas e pô-las em teoria (1985, p. 51-52). 
Piaget reconhece, portanto, que as estruturas mais gerais da "matemática moderna" são as mais abstratas, mas estas estruturas se apresentam "no espírito das crianças" sob a forma de manipulações concretas, materiais ou verbais. Ele diz que um matemático não acostumado à psicologia pode achar que as atividades concretas sejam um obstáculo à abstração, mas que um psicólogo está mais habituado a "distinguir cuidadosamente a abstração a partir dos objetos (fonte de experiência física, estranha à matemática) e a abstração a partir das ações, fonte da dedução e da abstração matemáticas" (1985, p. 53). Isto só corrobora a noção de que um emprego prematuro de excessiva linguagem formal e simbolismo técnico não produz uma educação sã. Assim, Piaget indicou que as crianças compreendiam as operações, naturalmente, primeiro em caráter manipulativo, depois estas seriam interiorizadas e, finalmente, passariam do concreto ao abstrato. Os processos evolutivos das estruturas cognitivas passam por períodos distintos e a passagem de um período para outro não se dá de forma imediata ou de forma que se possa desprezar o período anterior. Pelo contrário, a cada novo período ocorre uma ampliação da fase anterior, tornandoa mais rica e abrangente. Recorrer à ação, num modelo de educação piagetiano, não conduz a um simples empirismo, mas, por outro lado, prepara a dedução formal seguinte, desde que se tenha em mente que a ação, bem conduzida, pode ser operatória, bem como a formalização mais adiantada (CASTELNUEVO citado por FIORENTINO; MIORIM, 1993).

\section{A presença (ou ausência) de Rousseau, Pestalozzi e Piaget nas pesquisas brasileiras sobre o LEM}

Uma experiência que não seja realizada pela própria pessoa, com plena liberdade de iniciativa, deixa de ser, por definição, uma experiência, transformando-se em simples adestramento, destituído de valor formador por falta da compreensão suficiente dos pormenores das etapas sucessivas. (Jean Piaget, Para onde vai a educação?)

Cada um desses três pensadores, a seu modo e em seu tempo, reconheceu que a ação do indivíduo sobre o objeto é importantíssima para a aprendizagem. Essas ideias somadas a de outros educadores contribuíram para que, por volta dos 1980 no Brasil, a reflexão sobre o uso de materiais concretos e jogos no ensino da matemática ganhasse terreno. Naquele momento, e principalmente nas décadas seguintes, espaços reservados não só a aulas regulares, mas também para tirar dúvidas de alunos; para os professores planejarem suas atividades, discutirem seus projetos, para a criação e o desenvolvimento de atividades experimentais, 
para o armazenamento e a produção de materiais instrucionais que pudessem facilitar o aprimoramento da prática pedagógica foram sendo criados em universidades e escolas do país. Podemos constatar isso a partir das datas de criação de alguns desses laboratórios: o Laboratório de Ensino e Aprendizagem de Matemática e Ciências Físicas e Biológicas da Universidade Federal do Paraná e o Laboratório de Ensino de Matemática (LEM), do Instituto de Matemática, Estatística e Computação Científica (IMECC) da Universidade Estadual de Campinas (UNICAMP), ambos ativos desde 1985 e o Laboratório de Educação Matemática “Zaíra da Cunha Melo Varizo" da Universidade Federal de Goiás e o Laboratório de Ensino de Matemática da Universidade de São Paulo, criados na década de 1990.

Esses ambientes permitiram experimentar atividades que valorizavam observações, constatações, descobertas e o levantamento de hipóteses e a elaboração e testagem de estratégias que, às vezes, não estavam previstas nos planejamentos nem eram do conhecimento de professores que levavam suas turmas da escola básica para assistirem aulas ali. Além disso, como esses espaços estavam inseridos em faculdades e universidades, normalmente assistidas por projetos de investigação e por programas de pós-graduação, tornaram-se também espaços de formação inicial e continuada de professores e catalizadores de muitas pesquisas.

Procuramos, pois, em nosso estudo verificar como Rousseau, Pestalozzi e Piaget se fazem presentes nessas pesquisas. Dos 31 trabalhos de mestrado e doutorado que tivemos acesso observamos que quase todos, 30 trabalhos, ou seja, 96,77\%, apresentam em suas justificativas para as propostas de trabalho envolvendo o LEM argumentos que convergem, ou aproximam-se, ou são compatíveis com as propostas educacionais de ao menos um dos três pensadores apresentadas em nossa seção anterior. Esta conclusão seria óbvia se todos os trabalhos analisados tivessem em suas bases teórico-metodológicas referências aos trabalhos de Rousseau, Pestalozzi ou Piaget. Todavia, catorze monografias $(45,16 \%)$ não fazem qualquer referência a trabalhos ligados aos três ou mesmo às suas ideias ${ }^{3}$. Conquanto, mesmo sem citar diretamente os autores das dissertações e da tese analisadas, fazem referência, por exemplo, a algum dos textos da coletânea organizada por Sérgio Lorenzato - mencionada no início deste artigo.

\footnotetext{
${ }^{3}$ Nesse momento vale destacar que a simples menção ao nome de um dos três autores suíços não conta como uma referência às suas ideias como, por exemplo, na frase "Desenvolvido por Seymour Papert, um matemático que já havia trabalhado com Piaget em Genebra".
} 
Aquele "clássico" da Educação Matemática brasileira traz nos discursos dos seus autores a influência do modelo educacional pensado por Rousseau, Pestalozzi e Piaget ${ }^{4}$. O próprio Lorenzato (2006, p. 7), por exemplo, no capítulo primeiro do livro, diz que o LEM deve ser entendido como uma "sala-ambiente para estruturar, organizar, planejar e fazer acontecer o pensamento matemático, é um espaço para facilitar, tanto ao aluno como ao professor, questionar, conjecturar, procurar, experimentar, analisar e concluir, enfim, prender e principalmente aprender a aprender". Rêgo e Rêgo (2006), em outro artigo da coletânea, apontam que o uso de forma adequada de jogos, sucatas, embalagens, maquetes ou qualquer material que auxilie o aluno a desenvolver seus conhecimentos é muito importante, pois permite que os alunos ampliem "sua concepção sobre o que é, como e para que aprender matemática, vencendo os mitos e preconceitos negativos, favorecendo a aprendizagem pela formação de ideias e modelos” (p. 43). E para que estes materiais sejam usados de forma adequada, trabalhar com o LEM na formação de professores torna-se crucial. Nesse sentido, Bertoni e Gaspar (2006) indicam em seu texto daquela coletânea que os objetivos do LEM nos cursos de formação docente devem ser:

- dar oportunidade ao aluno de licenciatura em Matemática de aplicar e avaliar os conteúdos e as propostas pedagógicas discutidas nas disciplinas de formação profissional do currículo do curso de licenciatura em matemática /.../;

- subsidiar professores do ensino fundamental e médio em propostas pedagógicas, materiais didáticos e uso de novas tecnologias no ensinoaprendizagem da Matemática;

- criar situações que possam levar a despertar nos alunos, professores e membros da comunidade o interesse pelo conhecimento matemático e possam modificar algumas das concepções que se tem da Matemática, como, por exemplo, de que é um conhecimento que não é acessível a todos, que a Matemática é difícil etc. (p. 150)

Entre as pesquisas de mestrado e doutorado analisadas, além das referências aos textos dessa coletânea citada acima - que, entendemos ter afinidade com as propostas pedagógicas de Rousseau, Pestalozzi e Piaget que sustentam as abordagens de ensino envolvendo o LEM -, percebemos em muitas delas argumentos e justificativas que valorizam o uso do LEM em consonância com as propostas dos três educadores suíços a partir de outras diferentes referências. Oliveira Neto (2010), por exemplo, citando Fiorentini (1995), descreve como possibilidade para o ensino de matemática a perspectiva "empírico-ativista", na qual o aluno passa a ser considerado o centro do processo de ensino, valorizando a descoberta e o princípio

\footnotetext{
${ }^{4} 22$ dos 31 trabalhos (70,96\%) analisados citam algum artigo desse livro.
} 
de que se aprende fazendo. Assim, os métodos de ensino devem se pautar em atividades, valorizando a ação, a manipulação e a experimentação. Ou seja, o ensino estaria baseado em atividades desencadeadas pelo uso de jogos, situações lúdicas e experimentais e materiais manipulativos. Oliveira (2004) enfatiza que não só o LEM, mas também a sala de aula precisam ser espaços diferenciados: locais que permitam uma abordagem "onde os alunos trabalham de maneira informal, ou seja, se movimentam, discutem, opinam e fazem descobertas" (p. 23). E acrescenta que a abordagem deve permitir ao aluno se envolver em experiências matemáticas e que ele tenha acesso a materiais concretos com o objetivo de desenvolver uma atitude de questionar e, então, descobrir princípios, padrões e procedimentos matemáticos. Turrioni (2004), por sua vez, diz que, se bem planejado, um determinado uso de determinado material didático num LEM pode possibilitar ao estudante a "realização de observações, constatações, descobertas e até mesmo o levantamento de hipóteses e a elaboração e testagem de estratégias, que às vezes, não estavam previstas no planejamento nem eram do conhecimento do professor" (p. 67). Ela ainda aponta que ao se iniciar uma atividade num LEM, a "indagação" deve ser a primeira etapa, porque na busca por hipóteses sobre as causas e as consequências de um fenômeno ou problema, aparece a necessidade de levantar dados que permitam a refutação ou aceitação dessas hipóteses e conclui que "a obtenção de dados sugere a experimentação e esta leva a um conhecimento melhor de uma determinada realidade" (p. 70). E o trabalho mais antigo dos que tivemos consultado, o de Oliveira (1983), tem como única citação direta a um dos três autores suíços em destaque neste artigo o trecho de uma obra de Piaget usado como epígrafe do capítulo em que defende o uso do LEM em cursos de formação de professores. Além da epígrafe (a mesma escolhida para abrir a seção 3 deste artigo), Oliveira (1983) buscou inspiração, entre outros autores, em Hassler Whitney e Morris Kline para dizer que é necessário que o aluno raciocine e experimente por conta própria e seria o LEM o local ideal para que oportunidades de participação ativa do aluno surgissem no processo de ensino e de aprendizagem. Citando Morris Kline, ela acrescenta que laboratório possibilita ao aluno algo fundamental: que ele "raciocine e experimente por conta própria" (OLIVEIRA, 1983, p. 83).

Com exceção dos que fazem uso daquela citação de Sérgio Lorenzato (2006) - ou outra de suas edições - indicada no princípio deste texto, apenas dois trabalhos fazem referência também a Rousseau, Pestalozzi ou Piaget e suas ideias: Colonese (2014) e Nunes (2010). O primeiro dedica um capítulo às contribuições ao longo dos séculos para justificar o desenvolvimento de um ambiente de laboratório, experimental e investigativo, no ensino e aprendizagem da matemática. Além de indicar contribuições de Comenius, Montessori, EM TEIA - Revista de Educação Matemática e Tecnológica Iberoamericana - vol. 8 - número 1 - 2017 
Froebel, Locke, Dewey e outros, Colonese (2014) destaca que as ideias de Rousseau devem fazer os educadores refletirem sobre o tipo e a natureza de raciocínio em cada fase de seu desenvolvimento, sobre a importância de selecionar e desenvolver assuntos adequados a cada faixa etária e sobre o papel da memória e do raciocínio na aprendizagem e no desenvolvimento. E sobre Pestalozzi e Piaget, Colonese (2014) diz que

Pode-se identificar como um de seus princípios educativos mais significativos para o ensino da Matemática: a atividade como o ponto central de toda a metodologia de trabalho, centrada nos interesses e necessidades da criança e respeitando seu ritmo natural de desenvolvimento cognitivo, social e moral. Pestalozzi contribui, assim, para a compreensão da necessidade de uma aprendizagem escolar ativa, valorizando as atividades manuais e práticas, importantes para o desenvolvimento intelectual e moral da criança. (p. 45)

Piaget contribui não para pensar os materiais didáticos, mas para pensar o que propor às crianças com estes objetos e como propor discussões sobre as explorações sensoriais, operatórias e abstratas que realizarem sobre os mesmos. (p. 60)

Para Piaget /.../ o jogo além de proporcionar diversão e prazer pode proporcionar uma melhor compreensão e autonomia ao estudante quando ele enfrenta a resolução de problemas matemáticos ou científicos. (p. 61)

A tese de Nunes (2010), por outro lado, é mais sucinta do que a dissertação de Colonese ao discorrer sobre as contribuições dos três pensadores suíços e de outros pensadores ao trabalho no LEM. A autora diz que as ideias fundadas em Rousseau e em Pestalozzi destacam o aspecto metodológico da didática com foco no desenvolvimento integral do estudante e que a valorização da infância implica em consequências para a pesquisa e a ação pedagógicas. Nunes (2010) apresenta sua concepção de ensino de matemática pautada na resolução de problemas e, para tanto, destaca a seguinte citação de Schroeder e Lester (1989):

No ensino via resolução de problemas, os problemas são trabalhados não apenas com o propósito de se aprender Matemática, mas também como o principal meio de se fazer isso. Nessa abordagem, o ensino de um tópico de Matemática começa com uma situação problema que incorpora aspectos chave do tópico, e técnicas matemáticas são desenvolvidas como respostas razoáveis a problemas razoáveis. Um objetivo de se aprender Matemática é o de transformar certos problemas não rotineiros em rotineiros. A aprendizagem matemática, nessa forma, pode ser vista como um movimento do concreto (um problema do mundo real que serve como um exemplo de conceito matemático ou de técnica matemática) para o abstrato (uma representação simbólica de uma classe de problemas e técnicas para operar com estes símbolos). (Schroeder e Lester, 1989, p. 33) (NUNES, 2010, p. 83). 
Desse modo entendemos que Nunes (2010) aproxima a sua concepção de ensino de matemática através da resolução de problemas às indicações de Pestalozzi. Este dizia que os métodos deveriam partir do concreto para o abstrato, do sensível (e da experimentação), para a teoria. E de Piaget que as crianças compreendiam as operações de forma natural, de caráter manipulativo, para depois elas serem interiorizadas.

\section{Considerações Finais}

Nos séculos XVIII, XIX e XX Rousseau, Pestalozzi e Piaget consideraram a educação ideal como um processo natural do desenvolvimento da criança ao apoiar o jogo, o trabalho manual, a experiência direta sobre coisas. Sugeriram também uma escola que valorizasse os aspectos biológicos e psicológicos do aluno em desenvolvimento: o sentimento, o interesse, a espontaneidade, ênfase em atividades tais como canto, desenho, modelagem, excursões ao ar livre, manipulação de objetos. Nessas atividades as descrições deveriam preceder as definições: o conceito deveria nascer da experiência direta e das operações sobre as coisas desde que as atividades tenham sido bem conduzidas, preparando o aluno para as posteriores deduções formais que algumas disciplinas exigiam.

A partir da leitura de alguns relatórios de dissertações e teses brasileiras relacionadas com o ensino no ambiente do laboratório de ensino de matemática, no uso de jogos e de materiais manipulativos, identificamos que quase todos os trabalhos observados fazem alguma referência direta a Rousseau, Pestalozzi ou Piaget ou a ideias que eles defendiam. Apenas um dos trabalhos analisados não fez qualquer referência aos autores ou às propostas pedagógicas que entendemos sustentar o ensino na concepção de LEM apresentada no início deste artigo. O problema nesse caso, segundo entendemos, está justamente no fato de que a reflexão teórico-metodológica deve fazer parte da formação da pós-graduação, especialmente quando o resultado final de uma pesquisa - caso do trabalho em questão - envolve propostas de ensino para a educação básica que, infelizmente, estão sedimentadas no que se pode chamar de "senso comum" ou "discursos vazios".

Verificamos, por outra parte, que mesmo que não fazendo referências diretas aos nomes ou aos trabalhos de Rousseau, Pestalozzi e Piaget, as pesquisas de mestrado e doutorado analisados buscaram, quase todas, sustentar suas propostas que discutem o LEM como um espaço formativo e educativo em uma literatura que traz argumentos alinhados aos dos três autores. Não pudemos determinar se essa literatura está enraizada na pedagogia suíça que tem esses três nomes como símbolos, mas é notável a grande influência deles sobre os 
modelos de ensino idealizados pelas várias correntes pedagógicas que surgiram nos últimos dois séculos. Mais importante que perceber se há citações a três ícones da história da educação, foi interessante notar que boa parte das pesquisas brasileiras sobre o LEM analisadas apropriou-se de um ideário independente de indicação de filiação ou reverência.

\section{Referências}

BERTON, N. E.; GASPAR, M. T. J. LEM da Universidade de Brasília: uma trajetória de pesquisa em Educação Matemática, apoio à formação do professor e interação com a comunidade. In: LORENZATO, S. (Org.). LEM na formação de professores. Campinas, SP: Autores Associados, 2006, pp. 135-152.

COLONESE, P. H. O Laboratório de Construção do Saber Matemático na Universidade Severino Sombra: do Sonho à Realidade. 2014. Dissertação (Mestrado em Educação Matemática) - Programa de Pós-Graduação Stricto Sensu do Mestrado Profissional em Educação Matemática da Universidade Severino Sombra, Vassouras/RJ, 2014.

FIORENTINI, D. Alguns Modos de Ver e Conceber o Ensino de Matemática no Brasil. Zetetiké, Campinas, ano 3, n. 4, pp. 1-37, 1995.

FIORENTINI, D.; MIORIM, M. A. Uma reflexão sobre o uso de materiais concretos e jogos no ensino da matemática. Boletim SBEM, Brasília, ano 4, n. 7, pp. 4-9, 1993.

GOLDENBERG, M. A arte de pesquisar: como fazer pesquisa qualitativa em Ciências Sociais. Rio de Janeiro: Record, 2003.

GOMES, S. C. Teorias de aprendizagem em matemática: um estudo comparativo à luz da Teoria da Objetificação. 2016. Tese (Doutorado em Educação) - Programa de Pós-graduação em Educação, Universidade Federal do Rio Grande do Norte, Natal, 2016.

GROSS, R.; GRAMINHO, C. Rousseau e a educação da infância. In: VII CONGRESSO Nacional e Educação - EDUCERE. Anais... Curitiba, 2007, pp. 192-202.

LORENZATO, S. LEM e materiais didáticos manipuláveis. In: (Org.). O LEM na formação de professores. Campinas, SP: Autores Associados, 2006.

MESQUIDA, P. O Método em Pestalozzi: a matemática como caminho para a verdade. HISTEMAT. Brasília, Ano 2, n. 1, pp. 19-39, 2016.

NUNES, C. B. O Processo Ensino-Aprendizagem-Avaliação de Geometria através da Resolução de Problemas: perspectivas didático-matemáticas na formação inicial de professores de matemática. 2010. Tese (Doutorado em Educação Matemática) - Instituto de Geociências e Ciências Exatas, Universidade Estadual Paulista, Rio Claro/SP, 2010. 
OLIVEIRA NETO, J. A. Oficina de Máquinas: uma maneira de ensinar matemática para alunos do ensino médio. 2010. Dissertação (Mestrado Profissionalizante em Ensino de Ciências Exatas) - Centro de Ciências Exatas e Tecnológicas, Universidade Federal de São Carlos, São Carlos/SP, 2010.

OLIVEIRA, A. M. N. Laboratório de Ensino e Aprendizagem em Matemática: as razões de sua necessidade. 1983. Dissertação (Mestrado em Educação) - Universidade Federal do Paraná, Curitiba, 1983.

OLIVEIRA, S. S. Temas regionais em atividades de geometria: uma proposta na formação continuada de professores de Manaus (AM). 2004. Dissertação (Mestrado em Educação Matemática) - Instituto de Geociências e Ciências Exatas, Universidade Estadual Paulista, Rio Claro, 2004.

PESTALOZZI, J. H. Cartas sobre educação infantil. Madrid: Tecnos S.A., 1988.

PIAGET, J. La Epistemología Genética. Barcelona: A. Redondo, D.L., 1970.

PIAGET, J. Psicologia e Pedagogia. 7. ed. Rio de Janeiro: Forense Universitária, 1985.

RÊGO, R. M.; RÊGO, R. G. Desenvolvimento e uso de materiais didáticos no ensino de matemática. In: LORENZATO, S. (Org.). O LEM na formação de professores. Campinas, SP: Autores Associados, 2006, pp. 39-56.

RODRIGUES, M. U.; SILVA, L. D.; FERREIRA, N. C. Clássicos da Educação Matemática nos cursos de Licenciatura em Matemática no Brasil. In: D’AMBROSIO, B.; MIARKA, R. (orgs.). Clássicos na educação matemática brasileira: múltiplos olhares. Campinas, SP: Mercado de Letras, 2016, pp. 301-346.

ROUSSEAU, J. Emílio ou Da Educação. Rio de Janeiro: Bertrand Brasil, 1992.

SOËTARD, M. Johann Pestalozzi. Recife: Massangana, 2010.

TURRIONI, A. M. S. O Laboratório de Educação Matemática na Formação inicial de professores. 2004. Dissertação (Mestrado em Educação Matemática) - Instituto de Geociências e Ciências Exatas, Universidade Estadual Paulista, Rio Claro/SP, 2004. 